\begin{tabular}{l} 
Sharif University of Technology \\
Scientia Iranica \\
SCIENTIA \\
IRAN \\
Thansactions A: Civil Engineering \\
\hline
\end{tabular}

\title{
Simulating structural responses of a generic AAR-affected arch dam considering seismic loading
}

\author{
M. Lamea ${ }^{\mathrm{a}, *}$ and H. Mirzabozorg ${ }^{\mathrm{b}}$ \\ a. Department of Civil Engineering, Kashan Branch-Islamic Azad University, Kashan, P.O. Box 87135/433, Iran. \\ b. Department of Civil Engineering, K.N. Toosi University of Technology, Tehran, P.O. Box 1996715433, Iran. \\ Received 6 December 2015; received in revised form 22 April 2017; accepted 31 July 2017
}

\author{
KEYWORDS \\ Alkali-aggregate \\ reaction; \\ Concrete arch dams; \\ Finite-element \\ method; \\ Seismic behavior; \\ Post-earthquake \\ performance.
}

\begin{abstract}
$\overline{\text { Abstract. Alkali-Aggregate Reaction (AAR) is a deteriorative phenomenon for concrete }}$ that affects the performance of structures. This study focuses on seismic and postearthquake behaviors of an AAR-affected dam. A computer program is developed for simulating the structural behavior of AAR-affected dams including the seismic and postearthquake durations. A thin high double-curvature arch dam is selected as a case study and is modelled in a series of analyses within the assumed 30-year operating period. Each analysis includes an earthquake excitation in a different specified time. In each analysis, the seismic record is applied to the dam at different statuses of AAR progression, considering the proposed ARI index. The results show that AAR affects seismic performance of the dam, i.e., with the AAR progression, the dynamic responses are significantly changed. On the other side, the effect of earthquake occurrence time on the dam post-earthquake behavior is not noticeable. This may be explained by the linear elastic behavior assigned to the body material in the provided FE model.
\end{abstract}

(C) 2018 Sharif University of Technology. All rights reserved.

\section{Introduction}

The AAR-affected dams show unusual behavior that is intensified with the passage of structure lifetime. This different behavior originates from two main factors: the AAR gel expansion and degradation of the concrete mechanical properties. Both of the aforementioned factors are time dependent. On the other side, seismic loading is followed by significant effects on the structural reactions of any dam. With such a point of view, coupling between AAR effects and seismic loading, i.e. seismic loading effects on the performance of the AAR-affected dam and AAR effects on seismic responses, is probable which is followed as a subject for

*. Corresponding author. Tel.: +9821 88779623 E-mail addresses: m_lamea@dena.kntu.ac.ir (M. Lamea); mirzabozorg@kntu.ac.ir (H. Mirzabozorg)

doi: $10.24200 /$ sci. 2017.4230 the current research. Several studies have been carried out previously on AAR-affected structures. However, few of them had tendencies towards the dynamic performances.

The earliest phenomenological model presented by Charlwood et al. [1] has been widely used to analyze AAR-affected dams. Some researchers worked on chemo-mechanical modeling of alkali-aggregate reaction $[2,3]$. Malla and Wieland modelled a rather small arch-gravity dam in both linear and nonlinear conditions. In their research, the volume expansion due to AAR was simulated using equivalent temperature and was taken uniform over the whole dam body [4]. Parvini et al. investigated the seismic behavior of an AAR-affected hydraulic structure as a case study. They conducted the dynamic analysis after a period of transient static one (considering AAR phenomenon). The analyses with AAR involved only the pre-earthquake duration; meanwhile, the postearthquake analysis was not included in the study [5]. 
Introducing a new phenomenological model for AAR, Saouma and Perotti developed a numerical computer program to simulate structural effects of AAR. Verifying the proposed model, they simulated an AARaffected arch-gravity dam, which led to accurate and reliable results. In their research, seismic behavior of the structure was not elaborated [6]. Grimal et al. used a numerical model developed by Electricité De France (EDF) and modelled the expansion in damaged structures successfully. The researchers considered the concrete creep, the stresses induced by the AAR gel, and the mechanical damage to predict the experimental behavior of several beams subjected to AAR [7]. Tokmechi studied the probability of crack distribution and cracked zones percentage due to Normal Alkali Silica Reaction in a sample RCC dam. He used Monte Carlo Method to solve the stochastic system. His study did not deal with seismic loads of the mentioned dam [8]. In the study presented by Jinting et al., the seismic safety of an arch dam suffering from aging effects was evaluated using a proposed model. The reduction in the structural safety and intensification of the tensile cantilever stresses were approved during the performed analyses [9]. Based on the Saouma's model, a chemodamage model was proposed by Pan et al. [10,11], and the model was used to analyze the long-term behavior of AAR-affected gravity dams and arch dams. A more complete review on modeling of AAR-affected cases are presented by Pan et al. [12].

In the current research, a computer code prepared previously by the authors was developed for analyzing the AAR-affected structures under seismic excitations. The program is based on the finite-element procedure and is able to analyze the structures in three different phases: pre-earthquake static (but transient) phase, dynamic analyses due to seismic loading, and resumption of the static analysis in the post-earthquake phase. During the static phases, AAR progression is numerically simulated following a sigmoid curve based on an adopted comprehensive AAR model. During the earthquake period, no growth in AAR gel or degradation in mechanical properties is expected; however, variations in the subsequent effects of the reaction are elaborated. In this regard, a new redistribution of the AAR gel expansion may be expected. This is due to the new imposed confinement (i.e., new stress state) during the seismic loading, which leads to changes in the AAR load vector. Furthermore, the material behavior is assumed to be linear elastic. Therefore, when one changes the earthquake excitation time, coupling between AAR and seismic loading and subsequent effects on the post-earthquake responses may be negligible. Nevertheless, the conditions may be different during the seismic loading. However, this point of view would be considered during the current research.

\section{Governing equations and ground motion loading}

Clearly, seismic loading of a dam-reservoir-foundation system is followed by a coupled problem. The coupled mathematical problem should be solved through the numerical procedures, such as Finite-Element method. In the aforementioned system, the Helmoltz equation governs the reservoir medium given as follows [13]:

$$
\nabla^{2} p=\frac{1}{C^{2}} \frac{\partial^{2} p}{\partial t^{2}},
$$

where $p, C$, and $t$ are hydrodynamic pressure, pressure wave velocity in the liquid domain, and time, respectively. For solving Eq. (1), the boundary conditions are required to be applied on the reservoir medium [14]. The equations of the dam-foundation (as the structure) and the reservoir take the following form:

$$
\begin{gathered}
{\left[\begin{array}{cc}
{[M]} & 0 \\
\rho[Q]^{T} & {[G]}
\end{array}\right]\left\{\begin{array}{l}
\ddot{U} \\
\ddot{P}
\end{array}\right\}+\left[\begin{array}{cc}
{[C]} & 0 \\
0 & {\left[C^{\prime}\right]}
\end{array}\right]\left\{\begin{array}{l}
\dot{U} \\
\dot{P}
\end{array}\right\}} \\
+\left[\begin{array}{cc}
{[K]} & -[Q] \\
0 & {\left[K^{\prime}\right]}
\end{array}\right]\left\{\begin{array}{l}
U \\
P
\end{array}\right\}=\left\{\begin{array}{c}
\left\{f_{1}\right\}-[M]\left\{\begin{array}{l}
\ddot{U}_{g} \\
\{F\}-\rho[Q]^{T}\left\{\ddot{U}_{g}\right\}
\end{array}\right\},
\end{array}\right.
\end{gathered}
$$

where $[M],[C]$, and $[K]$ are the mass, damping, and stiffness matrices of the structure including the dam body and its surrounding foundation medium; $[G],\left[C^{\prime}\right]$, and $\left[K^{\prime}\right]$ are matrices representing the mass, damping, and stiffness equivalent matrices of the reservoir, respectively. Matrix $[Q]$ is the coupling matrix; $\left\{f_{1}\right\}$ is the vector including both the body and the hydrostatic force; $\{P\}$ and $\{U\}$ are the vectors of hydrodynamic pressures and displacements, respectively, and $\left\{\ddot{U}_{g}\right\}$ is the ground acceleration vector.

In the current research, all three components of a ground motion record, scaled in DBE (design basis earthquake), are applied simultaneously to the provided finite-element model. For decreasing the computation cost, only the strong motion duration is elaborated. Figure 1 shows the time history of the aforementioned earthquake during strong motion interval.

The conducted seismic analyses include 583 steps with the time interval of 0.02 . For computing damping matrix using Rayleigh method, the damping ratio (proportional to the structure stiffness and mass matrices) is assumed $5 \%$, while $\alpha$ and $\beta$ factors are taken as 0.94248 and 0.00199 , respectively. It is worth mentioning that PGA is 0.2 for the horizontal components and 0.11 for the vertical direction based on the dam site specifications.

The utilized Newton-Raphson equilibrium iterations provide convergence at the end of each load increment within the defined tolerance limits. In this 


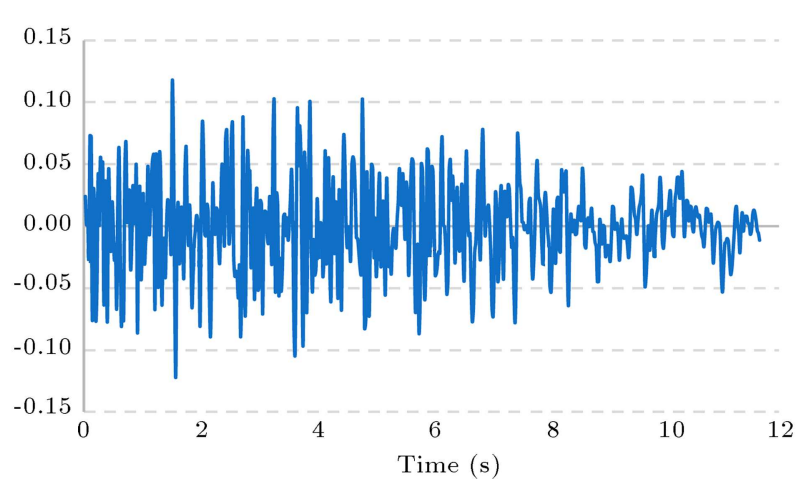

(a)

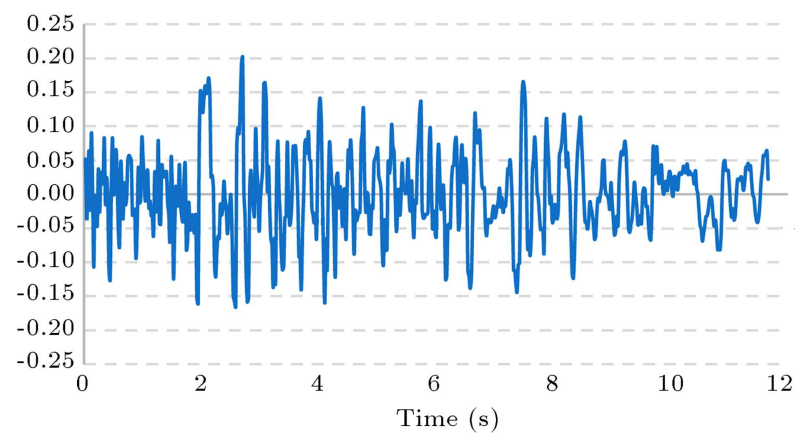

(b)

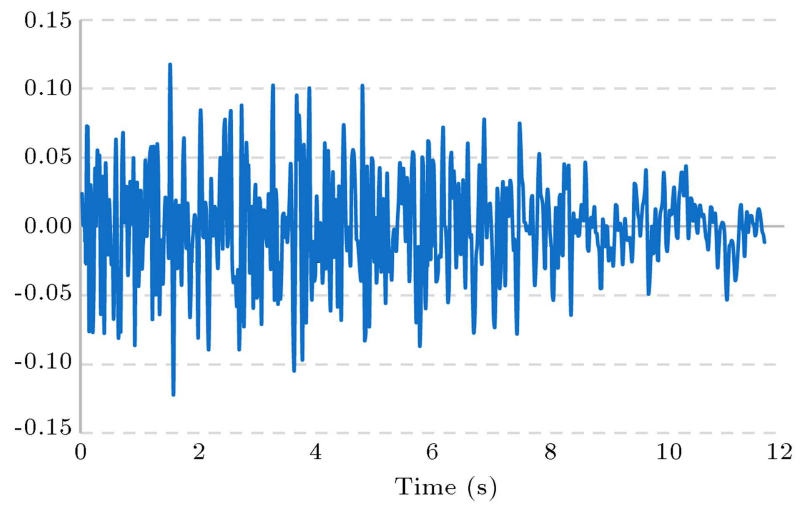

(c)

Figure 1. Scaled strong motion duration of the earthquake records in three directions: (a) Cross stream, (b) stream, and (c) vertical.

study, for the solid elements with concrete material, the convergence criteria are based on the force and displacement, while elements are based on the pressure for the reservoir fluid. For dynamic analyses, the Newmark- $\beta$ method is utilized for the direct integration of the coupled equations along the subsequent time steps.

\section{Formulation of the AAR model}

For simulating AAR effects within the current developed code, the phenomenological model of Saouma and Perotti is used. This model has a relatively comprehensive formulation involving various aspects of the reaction. It profits by both of state-of-the-art

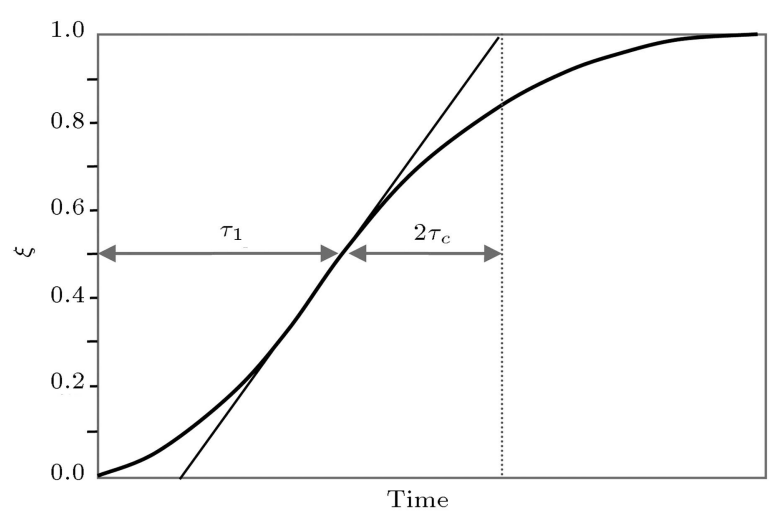

Figure 2. Reaction progression at a constant temperature [15].

theoretic and new experimental achievements. The reaction kinetics is assumed to follow a sigmoid curve (Figure 2), which is expressed by Eq. (3).

$$
\xi(t, \theta)=\varepsilon^{\mathrm{AAR}}(t) / \varepsilon_{\infty}^{\mathrm{AAR}}=\frac{1-\exp \left(-\frac{t}{\tau_{c}(\theta)}\right)}{1+\exp \left(-\frac{1-\tau_{l}\left(\theta, I_{\sigma}, f_{c}^{\prime}\right)}{\tau_{c}(\theta)}\right)},
$$

where $\xi$ is an index for AAR progression that ranges from 0 to 1, i.e., two limits for minimum and maximum reaction advancements; $t$ is the analysis time (or the dam lifetime); $\theta$ is the internal temperature of AARaffected material; finally, $\tau_{c}$ and $\tau_{l}$ are the characteristic and latency times, respectively (see Figure 2 for more details).

AAR has two main effects that affect the time history of structural responses: inflation of the AAR gel and degradation of the elastic modulus and tensile strength. Eq. (4) presents a relation for computing the expansion rate in every time step [15].

$\dot{\varepsilon}_{\mathrm{vol}}^{\mathrm{AAR}}(t)=\left.\Gamma_{t}\left(f_{t}^{\prime}, \sigma_{1}\right) \cdot \Gamma_{c}\left(\bar{\sigma}, f_{c}^{\prime}\right) \cdot f(h) \cdot \xi(t, \theta) \cdot \varepsilon^{\infty}\right|_{\theta=\theta_{0}}$,

where $\Gamma_{t}$ represents a descendent factor because of forming macro cracks. Similar effect is exerted by $\Gamma_{c}$ due to forming of micro cracks; $f(h)$ is the effect of moisture deficiency (may be taken as unity in the structures such as concrete dams); $\xi$ is attained by Eq. $(3) ; \varepsilon^{\infty}$ is the maximum of free volumetric expansion, measured in the reference temperature [15]. Considering Eq. (4) and through a simple finite difference method, the gel expansion value in every time step may be computed. The attained expansion value is indeed the free volumetric strain and should be distributed in linear free strains within the provided numerical procedure. This is performed by three corresponding weight factors, $w_{i}$, so that [15]:

$$
\varepsilon_{i}=w_{i} \varepsilon_{V}^{\mathrm{AAR}}, \quad i=1,2,3 .
$$

For example, the weight factor associated with princi- 
pal direction " $k$ " consists of $[15]$ :

$$
\begin{array}{r}
W_{k}=N_{1} W_{1}+N_{2} W_{2}+N_{3} W_{3}+N_{4} W_{4} \\
=\frac{1}{a b}\left\{\begin{array}{c}
\left(a-\sigma_{l}^{\prime}\right)\left(b-\sigma_{m}^{\prime}\right) \\
\sigma_{l}\left(b-\sigma_{m}^{\prime}\right) \\
\sigma_{l}^{\prime} \sigma_{m}^{\prime} \\
\left(a-\sigma_{l}^{\prime}\right) \sigma_{m}^{\prime}
\end{array}\right\}\left\{\begin{array}{l}
W_{1} \\
W_{2} \\
W_{3} \\
W_{4}
\end{array}\right\}
\end{array}
$$

According to Figure $3, w_{1}$ to $w_{4}$ correspond to nodes of the rectangle representing the current stress state; $a$ and $b$ are sides of this rectangle (see [15] for more details).

Following the aforementioned procedure, a vector of free strains is attained which leads to an additional force vector within the utilized finite-element procedure.

On the other side, AAR degrades the solidity and tensile strength of the AAR-affected concrete. In this regard, Eqs. (7) and (8) are proposed in the utilized model:

$$
\begin{aligned}
& E(t, \theta)=E_{0}\left[1-\left(1-\beta_{E}\right) \xi(t, \theta)\right], \\
& f_{t}(t, \theta)=f_{t, 0}\left[1-\left(1-\beta_{f}\right) \xi(t, \theta)\right],
\end{aligned}
$$

where $E_{0}$ and $f_{t, 0}$ are the initial elastic modulus and tensile strength, respectively. In addition, $\beta_{E}$ and $\beta_{f}$ are the corresponding residual fractional values when $\varepsilon_{\mathrm{AAR}}$ tends to $\varepsilon_{\mathrm{AAR}}^{\infty}$. The later equations, along with Eq. (4), describe the dependency of AAR-affected structure behavior on the dam lifetime. This may lead to different seismic behaviors for the structure when it experiences the same excitation at different moments

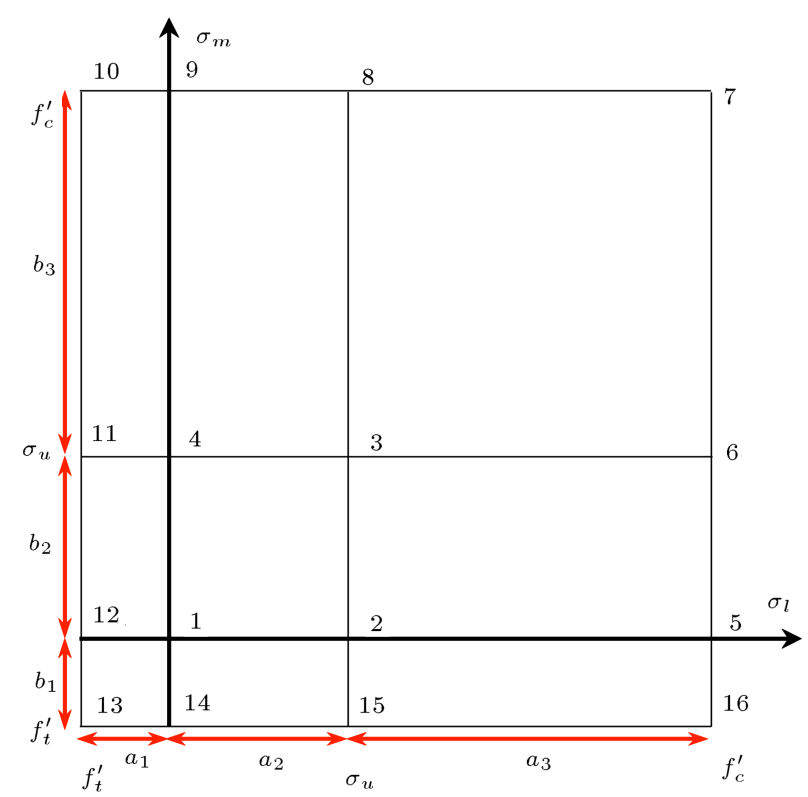

Figure 3. Stress regions for computing stress weight factors [15]. of its lifetime. This is the main challenge considered in the current study.

The currently developed computer program involves all of the formulations presented in Sections 2 and 3. The accuracy of this program in simulating AAR-affected concrete structures and seismic loading has been previously verified in the separate research $[14,16,17]$.

\section{Case study: Dez dam}

Dez dam is a thin double-curvature high arch dam located in $20 \mathrm{~km} \mathrm{NE}$ of Andimeshk, Iran (Figure 4(a)). Its height is $203 \mathrm{~m}$ from the foundation and $190 \mathrm{~m}$ from the riverbed. For the dam crown cantilever, the thicknesses at the crest elevation and base are $4.5 \mathrm{~m}$ and $21 \mathrm{~m}$, respectively. Crest length is $212 \mathrm{~m}$ and its altitude is 354 masl. After conducting the optimization program on the dam performance and hydropower generation plants, the reservoir's normal water level was raised up to 352 masl [18]. It is worth noting that the reinforced concrete saddle, referred to as pulvino, was provided between the dam body and foundation rock for facilitating distribution of the applied loads on the surrounding rock. Figure 4(b) shows the downstream view of the Dam and its surrounding environment.

In the provided Finite-Element model, the dam body and its pulvino are modelled using 648 and 144

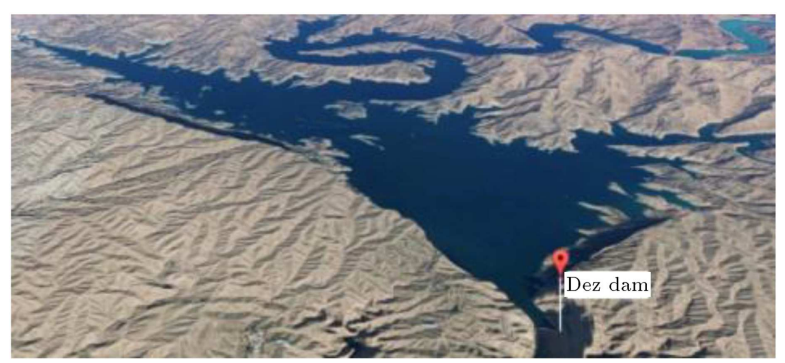

(a)

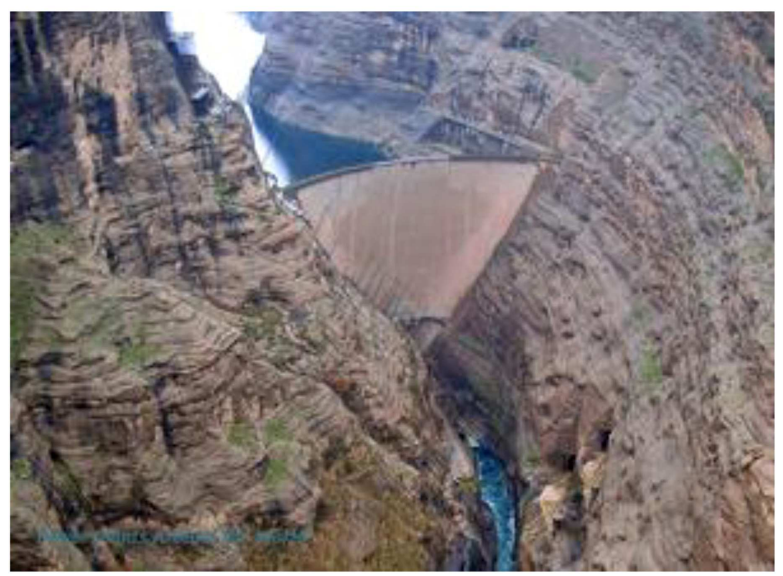

(b)

Figure 4. (a) Satellite photo of Dez dam and lake (Google map, 2017). (b) General view of dam, river, and reservoir [18]. 


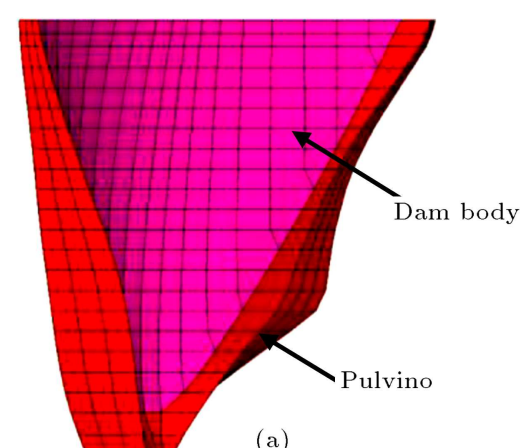

(a)

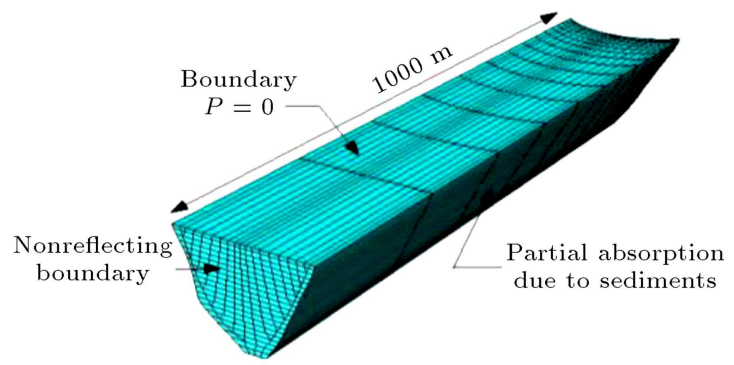

(b)
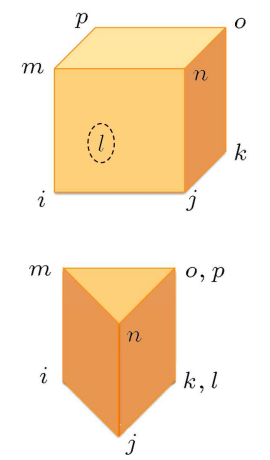

(d)

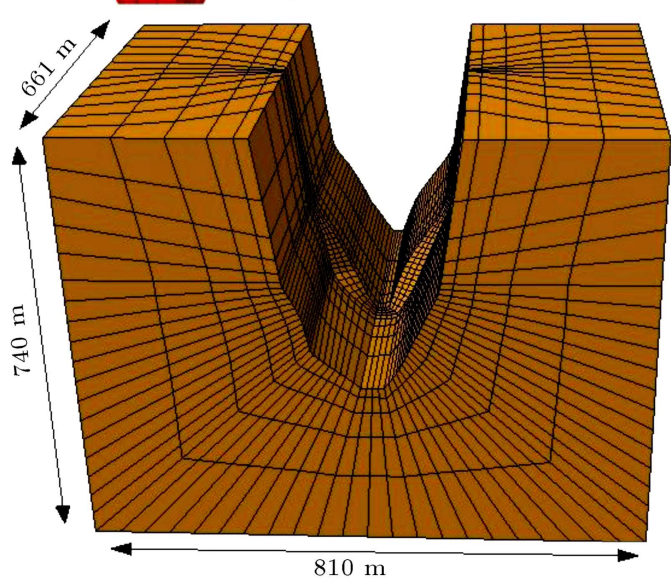

(c)

Figure 5. Details of the geometric modelling: (a) Finite-element mesh of the dam body, (b) FE mesh of the reservoir, (c) FE mesh of the foundation, and (d) cubed and prism solid-thermal elements.

elements, respectively (see Figure 5(a)). The dam foundation rock and reservoir affect the seismic analysis; they are modelled with 3770 and 3660 elements, respectively. Finally, the total number of elements in the model is 8522 (see Figure 5). The utilized elements for modelling the concrete dam, its pulvino and the foundation rock are 8-node brick elements with 8 integration points. Each node has three translational degrees of freedom in the global directions: $x, y$, and $z$. Furthermore, the reservoir is modelled using 8-node fluid brick elements. Pressure is the nodal degree of freedom for the fluid elements (Figure 5(b)).

Elasticity modulus, Poison's ratio, density and thermal expansion coefficient for the dam body concrete are assumed $40 \mathrm{GPa}, 0.2,2400 \mathrm{~kg} / \mathrm{m}^{3}$, and $6 \times$ $10^{-6} /{ }^{\circ} \mathrm{C}$, respectively. The moduli of deformations for the saturated and unsaturated parts of the foundation medium are taken $13 \mathrm{GPa}$ and $15 \mathrm{GPa}$, respectively. The pressure wave velocity in water is taken $1440 \mathrm{~m} / \mathrm{s}$, and the wave reflection coefficient for the reservoir peripheral boundary is assumed 0.8. All the abovementioned mechanical parameters were extracted from a comprehensive calibration procedure conducted on the provided model by the second author and his coworkers [18]. Table 1 shows a list of material properties assumed for modeling of the dam in static and dynamic conditions, separately.

The utilized values for parameters of the AAR
Table 1. Material properties of the mass concrete and foundation rock of Dez arch dam.

\begin{tabular}{lcc}
\hline \multicolumn{1}{c}{ Parameter } & Static & Dynamic \\
\hline$E_{\text {concrete }}(\mathrm{GPa})$ & 40 & 46 \\
$\rho_{\text {concrete }}\left(\mathrm{kg} / \mathrm{m}^{3}\right)$ & 2400 & 2400 \\
$\nu_{\text {concrete }}$ & 0.20 & 0.14 \\
$f_{t}^{\text {concrete }}(\mathrm{MPa})$ & 3.40 & 5.10 \\
$f_{c}^{\text {concrete }}(\mathrm{MPa})$ & 35.0 & 36.5 \\
$E_{\text {rock }}(\mathrm{GPa})$ & $13 \sim 15$ & $13 \sim 15$ \\
$\nu_{\text {rock }}$ & 0.25 & 0.25 \\
$\rho_{\text {water }}\left(\mathrm{kg} / \mathrm{m}^{3}\right)$ & 1000 & 1000 \\
$C_{\text {water }}(\mathrm{m} / \mathrm{s})$ & 1440 & 1440 \\
\hline
\end{tabular}

model are assumed as presented in Table 2. More details of these parameters may be found in the study by Saouma and Perotti [15].

\section{Analyses' results and discussion}

Developing the desired program and modeling the case study, a couple of analyses are conducted within the assumed 30-year operation period. All of the analyses involve both of the static (pre-earthquake and post-earthquake analyses) and dynamic phases (during earthquake occurrence) at the same procedure. The specified time for earthquake occurrence is different for 
Table 2. Values of AAR parameters based on the model of Saouma and Perotti.

\begin{tabular}{cccc}
\hline Parameter & Value & Parameter & Value \\
\hline$U_{c}$ & 5400 & $\beta$ & 0.5 \\
$U_{1}$ & 9400 & $\varepsilon^{\infty}$ & 0.00284 \\
$\beta_{E}$ & 0.75 & $\alpha$ & 1.33 \\
$\beta_{f}$ & 0.75 & $\theta_{0}$ & $238^{\circ} \mathrm{K}$ \\
$\Gamma_{t}$ & 0.18 & $\tau_{c 0}$ & 65.3 days \\
$\omega_{c}$ & 0.001 & $\tau_{l 0}$ & 185 days \\
$\Gamma_{r}$ & 0.1 & $\sigma_{u}$ & $10 \mathrm{MPa}$ \\
\hline
\end{tabular}

each analysis. The performed analyses are named here as follows:

- Case A: Earthquake occurs passing 1 years of the dam lifetime (with $\mathrm{ARI}=0.2 \%$ );

- Case B: Earthquake occurs passing 6 years of the dam lifetime (with $\mathrm{ARI}=20 \%$ );

- Case C: Earthquake occurs passing 9 years of the dam lifetime (with ARI=38\%);

- Case D: Earthquake occurs passing 12 years of the dam lifetime (with $\mathrm{ARI}=57 \%$ );

- Case E: Earthquake occurs passing 15 years of the dam lifetime (with $\mathrm{ARI}=73 \%$ );

- Case F: Earthquake occurs passing 26 years of the dam lifetime (with ARI=99\%).

It is worth mentioning that occurrence of the earthquake in the above cases is arranged to be on different ARI levels. ARI may be a suitable index to evaluate the reaction progression in any AARaffected dam. This index is proposed by the authors as the weighted average of the reaction kinetics index thorough all elements of the dam body and is computed using Eq. (9):

$$
\mathrm{ARI}=\frac{\sum_{n=1}^{n e l} V_{n} \cdot R I_{n}}{\sum_{n=1}^{n e l} V_{n}},
$$

where $V_{n}$ is volume of the $n$th element, $R I_{n}$ is the reaction kinetic index of the $n$th element, and nel is the total number of dam body elements. Figure 6 presents the diagram of ARI versus time for the modelled arch dam. This figure is prepared based on a similar transient static analysis. Indicated in Figure 6, AAR reaches its extreme level after 22 years passing the dam service life. The earthquake excitation times for all of the cases are marked in Figure 6. The analyses cover the occurrence of earthquake in different conditions of AAR progression in the considered dam.

It should be noted that a transient thermal analysis is performed before the structural analyses. Solar radiations were modelled in the aforementioned simulations using a precise formulation utilized by the authors during the previous studies [19,20]. Meanwhile,

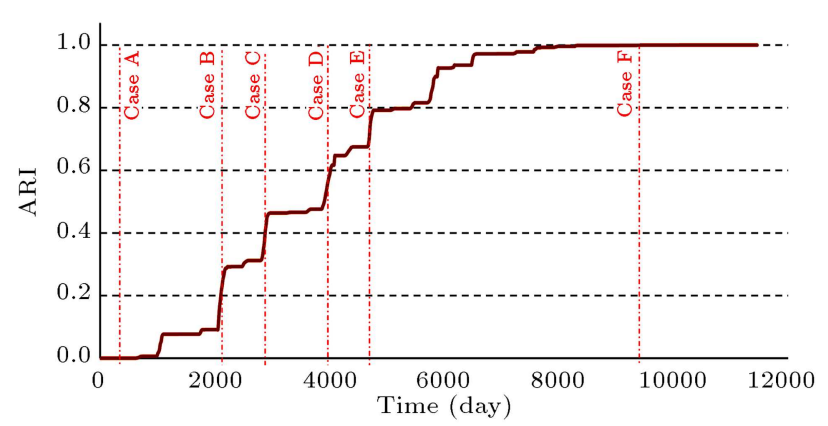

Figure 6. Diagram of ARI (Average of Reaction kinetic Index) for the analyzed case study.

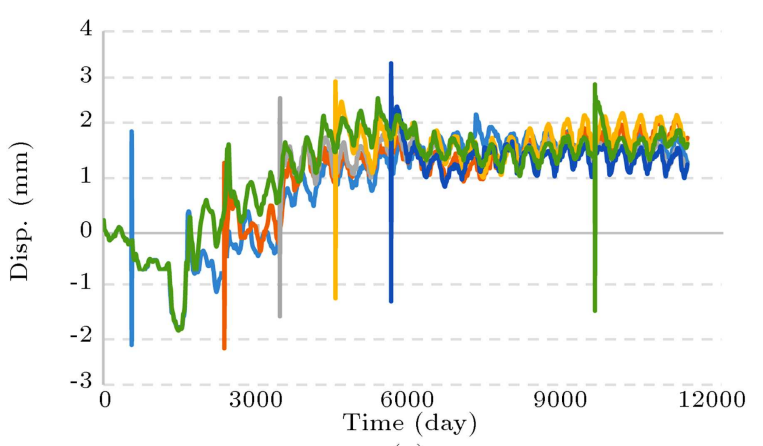

(a)

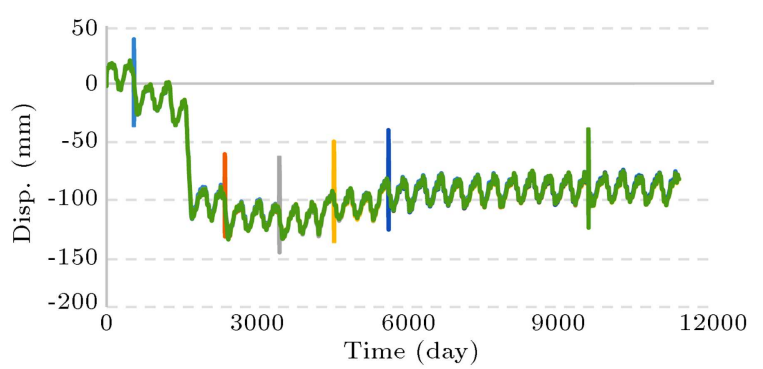

(b)

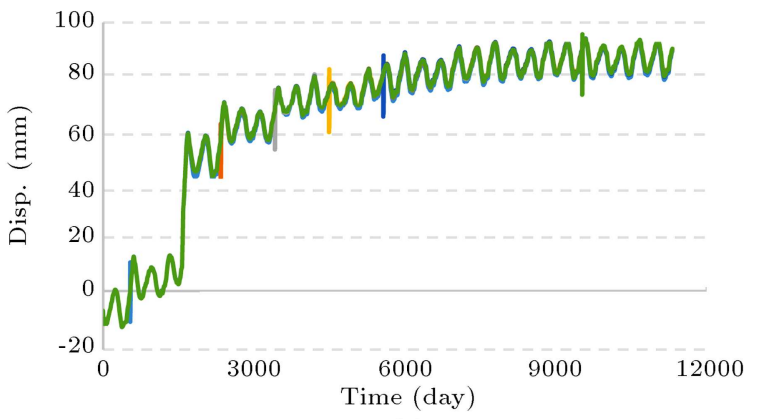

(c)

Figure 7. History of crest displacements in (a) cross-stream direction, (b) horizontal direction, and (c) vertical direction.

the variation of the reservoir surface level was elaborated based on the recorded history in the dam site. In all of the cases, seismic loading is assumed to occur in summer, which is commonly known as the critical season for earthquake excitations in arch dams.

Figure 7 shows the displacement history extracted 
from the performed analyses in all of the three directions: $x, y$, and $z$.

Indicated in the diagrams of Figure 6, it is inferred that the time of earthquake excitation does not affect the time history of post-earthquake crest displacements. However, when the stress contours of the final analyses steps (post-earthquake phase) are assessed, some few differences may be observed (see the contours in Figures 8 and 9 ).

The rest of the presented results include the structural responses during the seismic loading. Figures 10 and 11 show time history of the crest displacements
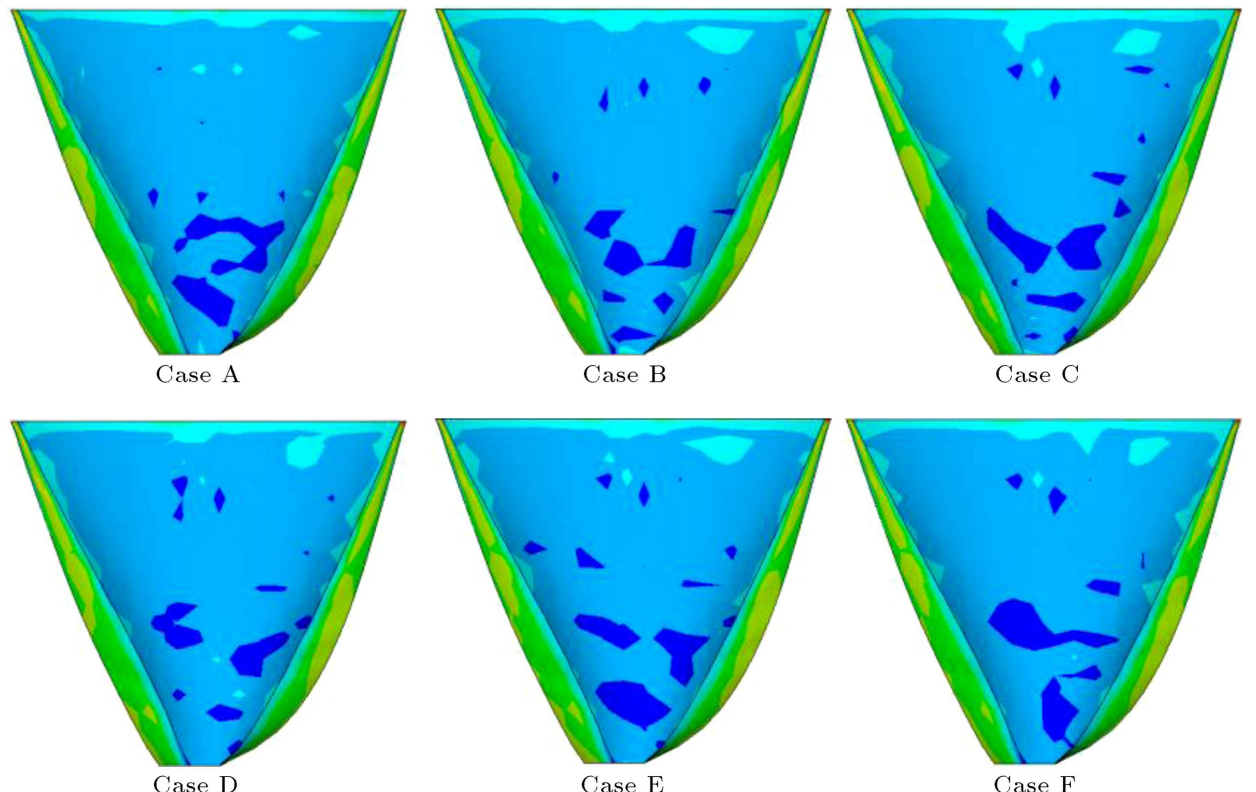

160139

$0.232 \mathrm{E}+08$ $0.309 \mathrm{E}+08$

$\begin{array}{llll}0.117 \mathrm{E}+08 & 0.193 \mathrm{E}+08 & 0.270 \mathrm{E}+08 & 0.347 \mathrm{E}+08\end{array}$

Figure 8. Contours of the 1st principal stresses at the last step of the analyses (in DS face, $\mathrm{Pa}$ ).
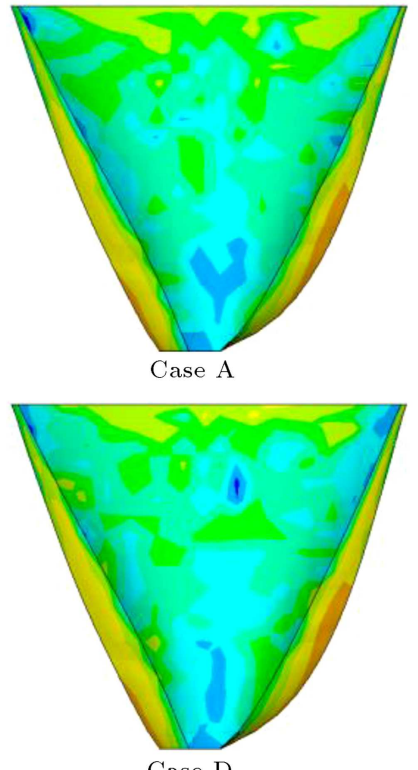

Case D
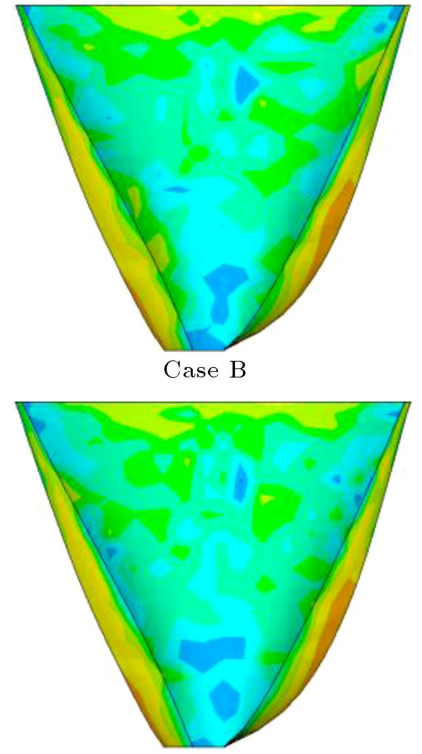

Case E
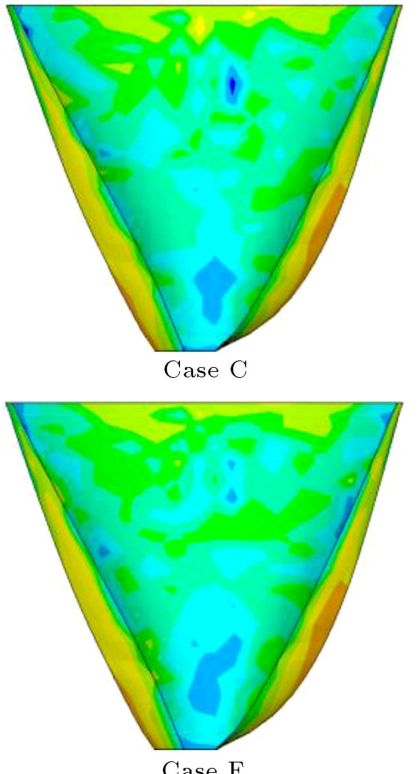

$0.102 \mathrm{E}+08$

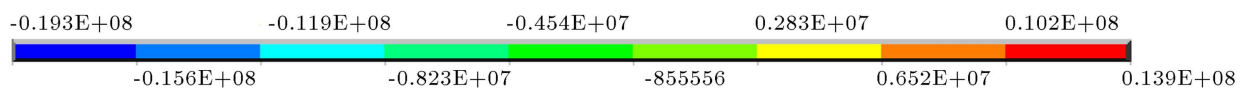

Figure 9. Contours of the 3rd principal stresses at the last step of the analyses (in DS face, Pa). 

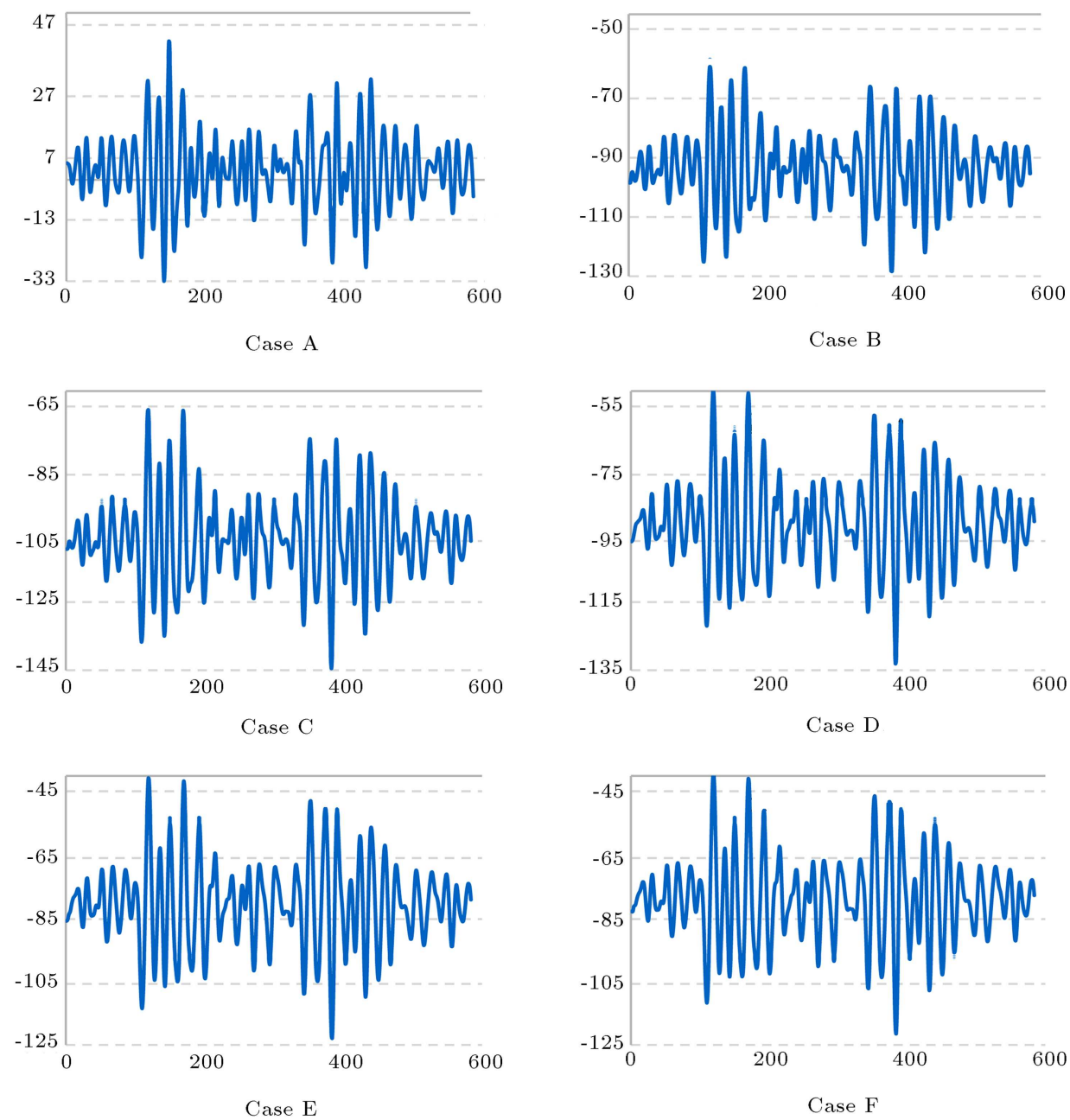

Figure 10. History of displacements in US/DS direction for all cases during earthquake (mm) (crest displacements versus analysis steps).

during earthquake for all of the performed analyses.

Non-concurrent Envelopes of the 1st and 3rd principal stresses during the earthquake excitation concerning all of the performed seismic analyses are presented in Figures 12 to 15.

Based on what is observed in Figures 12 to 15, the occurrence of the same earthquake at different moments of the lifetime would result in different reactions in the considered dam. In Table 3, a summary of the extreme values of Section 5 is presented.

The analyses' results imply that the occurrence of the same earthquake results in different seismic reactions in the considered dam. However, the effects are considerably milder when one considers the postearthquake responses. This may be explained by the assumption of linear elastic behavior for the body material. Simply, during the short period of the earthquake, there is not enough time for the AAR-affected concrete elements to experience further reduction in the elastic modulus. In other words, when one assumes nonlinear behavior for the model, impressibility of the post-earthquake responses is expected to be intensified. However, this part is left for development of the current research. The results presented in Section 5 show that estimating the responses of an AAR-affected dam is complicated when it experiences earthquake during its service life. Meanwhile, it is indicated that the critical or extreme values of the different structural responses do not occur in the same case. This perspective should receive more attention during the future extensions of the current study.

\section{Conclusion}

Using the new developed code, numerical simulations of AAR-affected dams are possible in both of the static and dynamic phases. Using the aforementioned computer program, several analyses, with assumption of the same earthquake excitation, were conducted. Each of the analyses includes simulation of the earthquake excitation at a different time step, which corresponds to different statuses for the AAR progression. The 

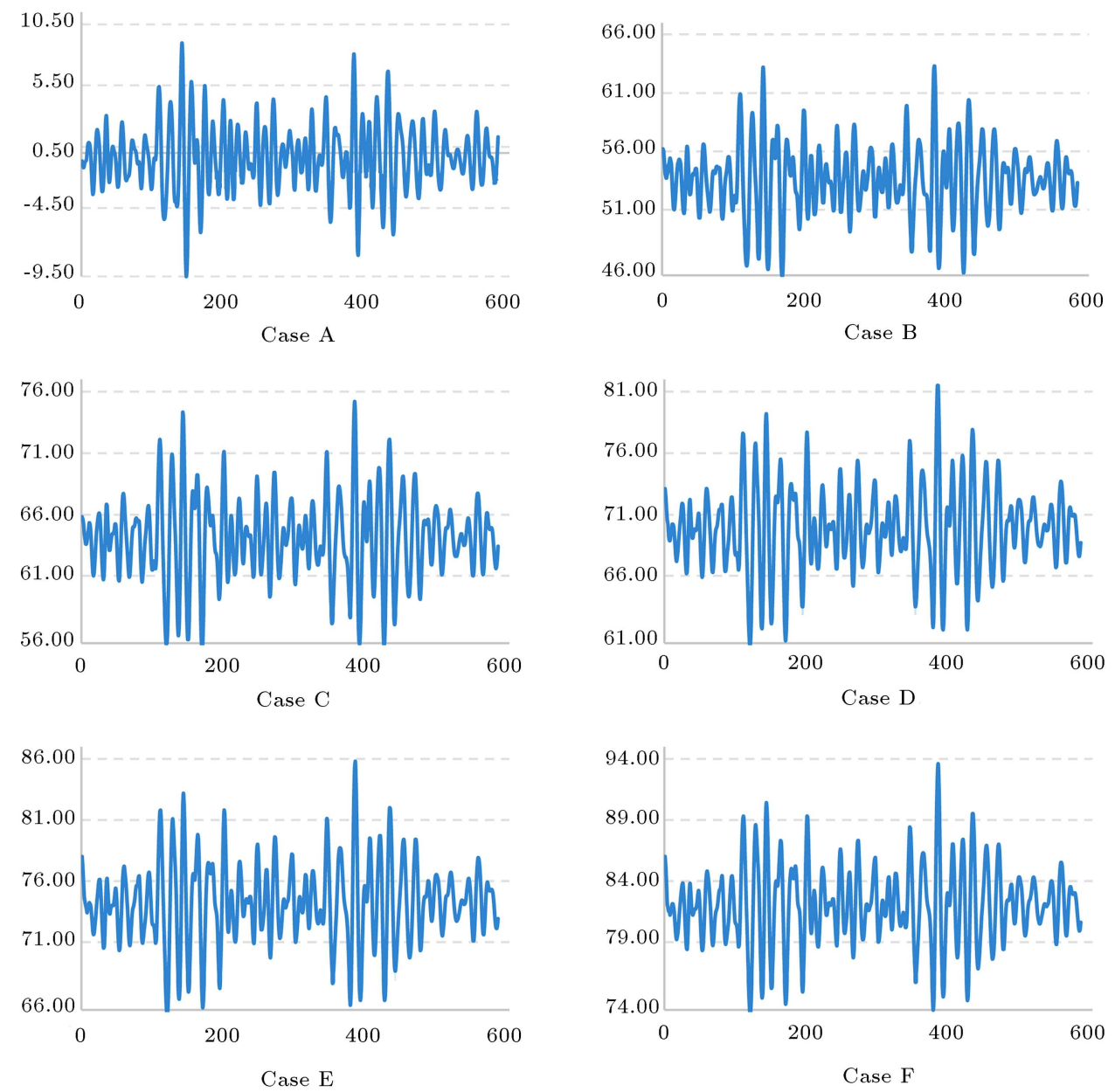

Figure 11. History of displacements in US/DS direction for all cases during earthquake (mm) (crest displacements versus analysis steps).

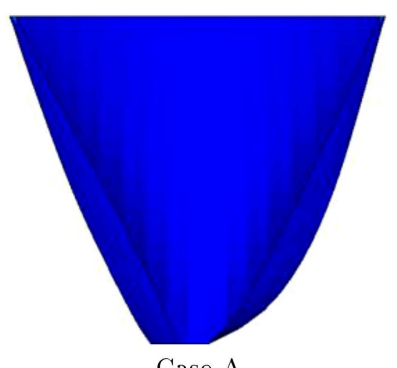

Case A

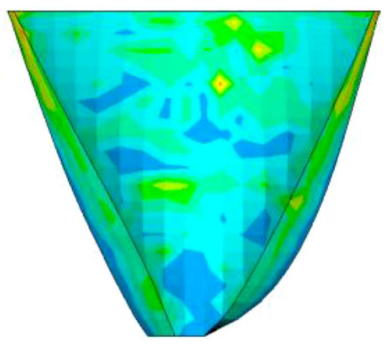

Case D

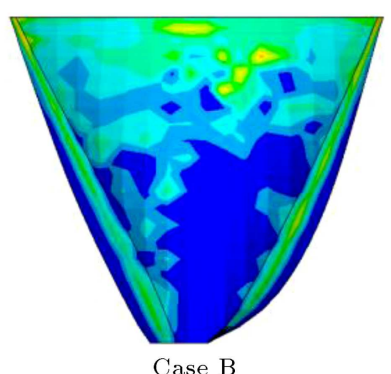

Case B

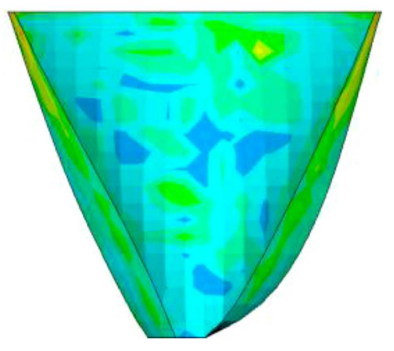

Case E
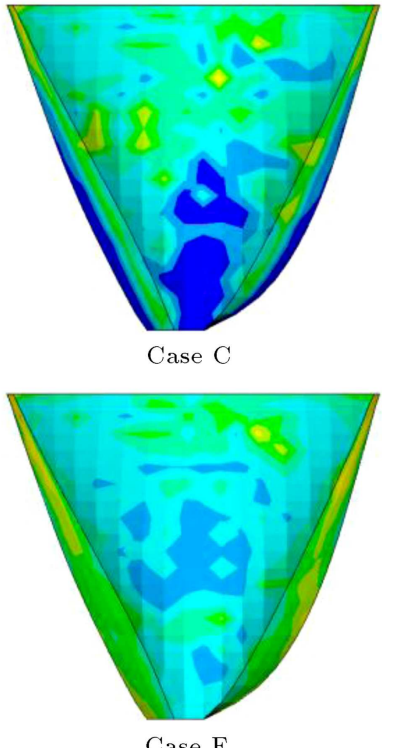

Case F

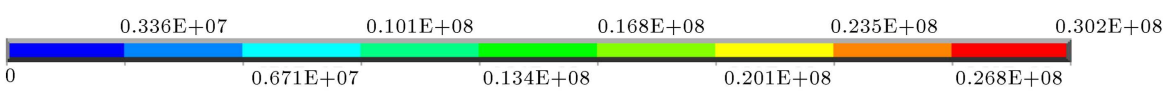

Figure 12. Envelopes of the 1st principal stresses on down-stream face. 


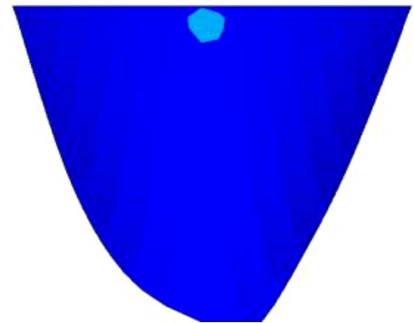

Case A

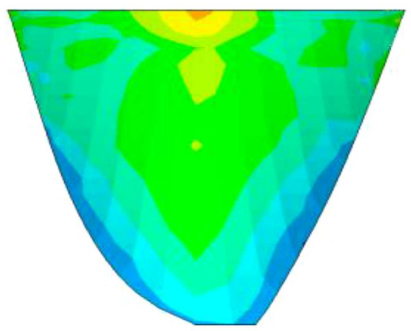

Case D

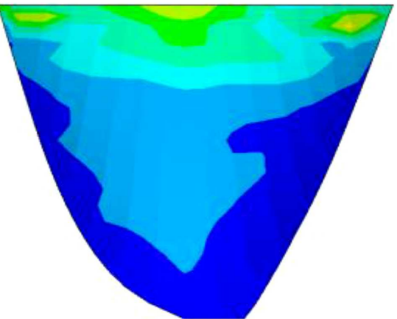

Case B

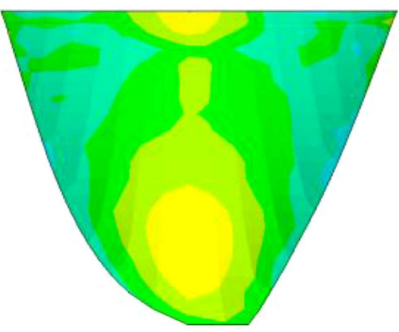

Case E

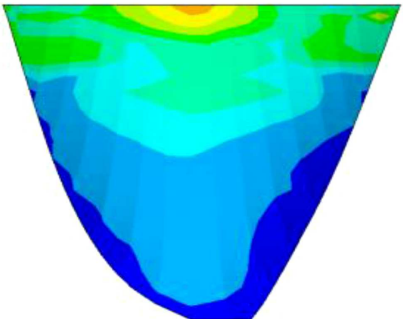

Case C

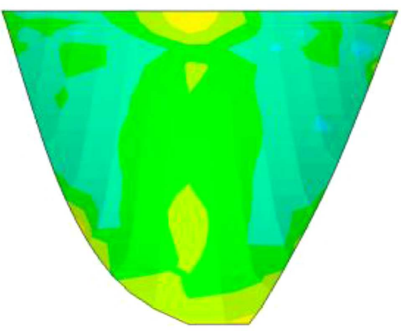

Case F

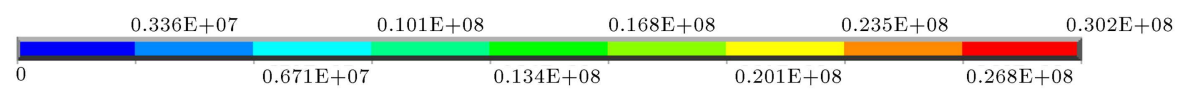

Figure 13. Envelopes of the 1st principal stresses on up-stream face $(\mathrm{Pa})$.

Table 3. Summary of the analyses' results during earthquake.

\begin{tabular}{|c|c|c|c|c|c|c|c|c|c|c|c|}
\hline \multirow[t]{2}{*}{$\begin{array}{c}\text { Analysis } \\
\text { case }\end{array}$} & \multirow[t]{2}{*}{ 永 } & \multirow{2}{*}{\multicolumn{2}{|c|}{$\begin{array}{c}\text { Range for displacement } \\
\text { variations during } \\
\text { earthquake }\end{array}$}} & \multicolumn{2}{|c|}{$\begin{array}{c}\text { Envelope of } \\
\text { tensile } \\
\text { stresses } \\
\end{array}$} & \multicolumn{2}{|c|}{$\begin{array}{c}\text { Envelope of } \\
\text { compressive } \\
\text { stresses }\end{array}$} & \multicolumn{2}{|c|}{$\begin{array}{c}\text { Tensile } \\
\text { stresses in } \\
\text { the last step }\end{array}$} & \multicolumn{2}{|c|}{$\begin{array}{l}\text { Compressive } \\
\text { stresses in } \\
\text { the last step }\end{array}$} \\
\hline & & & & Min & Max & Min & $\operatorname{Max}$ & Min & Max & Min & Max \\
\hline Case A & 0.2 & $\begin{array}{l}\text { Horizontal } \\
\text { US/DS } \\
\text { Vertical }\end{array}$ & $\begin{array}{c}3.94 \\
74.50 \\
18.47\end{array}$ & 0 & 9.22 & -11.53 & -1.02 & 0.55 & 29.3 & -19.3 & 13.6 \\
\hline Case B & 20 & $\begin{array}{l}\text { Horizontal } \\
\text { US/DS } \\
\text { Vertical }\end{array}$ & $\begin{array}{c}3.43 \\
69.04 \\
17.40\end{array}$ & 0 & 28.5 & -33.19 & 0 & 0.91 & 33.2 & -15.6 & 13.6 \\
\hline Case C & 38 & $\begin{array}{l}\text { Horizontal } \\
\text { US/DS } \\
\text { Vertical }\end{array}$ & $\begin{array}{c}4.01 \\
78.29 \\
19.80\end{array}$ & 0 & 28.66 & -27.87 & 0 & 0.76 & 33.1 & -18.5 & 13.9 \\
\hline Case D & 57 & $\begin{array}{l}\text { Horizontal } \\
\text { US/DS } \\
\text { Vertical }\end{array}$ & $\begin{array}{c}4.17 \\
83.26 \\
20.80\end{array}$ & 3.09 & 29.01 & -21.87 & 0 & 0.16 & 33.8 & -18.4 & 13.7 \\
\hline Case E & 73 & $\begin{array}{l}\text { Horizontal } \\
\text { US/DS } \\
\text { Vertical }\end{array}$ & $\begin{array}{c}4.55 \\
82.19 \\
20.30\end{array}$ & 3.42 & 29.33 & -23.18 & 0 & 0.33 & 34.7 & -15.9 & 13.8 \\
\hline Case F & 99 & $\begin{array}{l}\text { Horizontal } \\
\text { US/DS } \\
\text { Vertical }\end{array}$ & $\begin{array}{c}4.35 \\
81.85 \\
19.90\end{array}$ & 3.71 & 30.20 & -24.64 & 0 & 0.72 & 34.6 & -17.5 & 13.7 \\
\hline $\begin{array}{r}\text { Relative } \\
\text { difference }\end{array}$ & & $\begin{array}{l}\text { Horizontal } \\
\text { US/DS } \\
\text { Vertical }\end{array}$ & $\begin{array}{l}32.7 \\
20.6 \\
16.7\end{array}$ & - & 228 & 188 & - & 468 & 18.4 & 23.7 & 2.2 \\
\hline
\end{tabular}




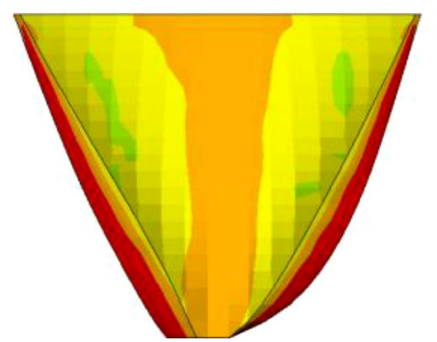

Case A

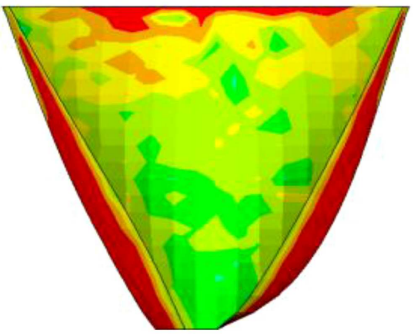

Case D

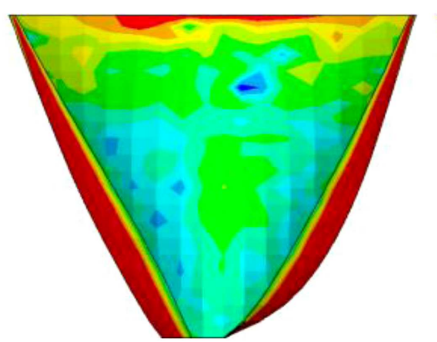

Case B

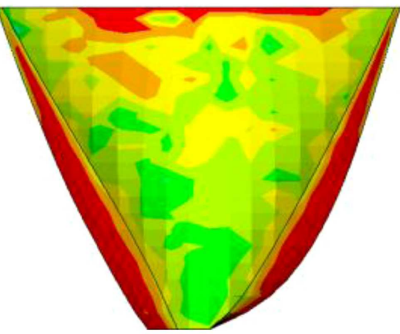

Case E

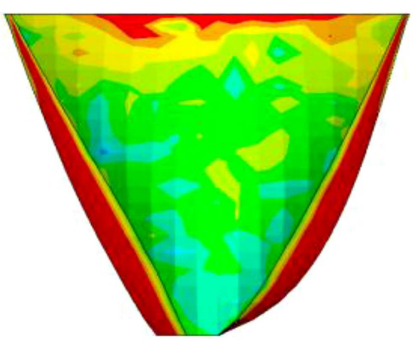

Case C

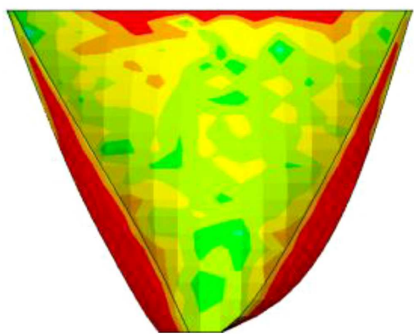

Case F

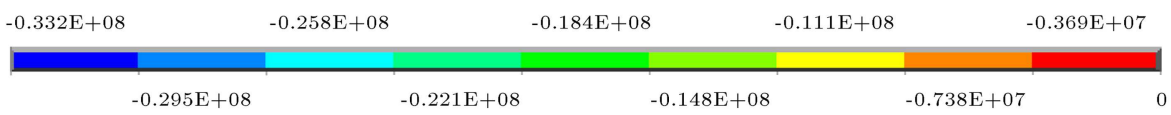

Figure 14. Envelopes of the 3rd principal stresses on down-stream face $(\mathrm{Pa})$.

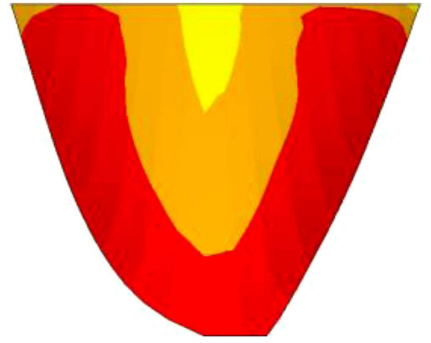

Case A

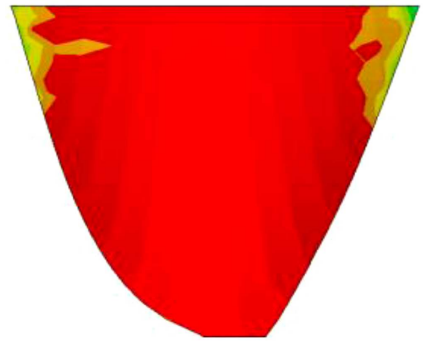

Case D

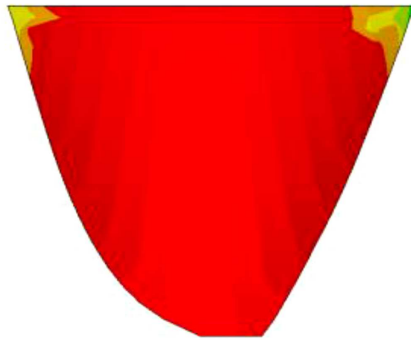

Case B

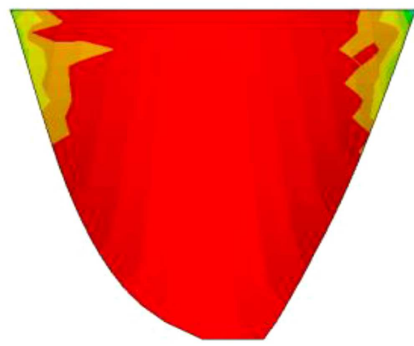

Case E
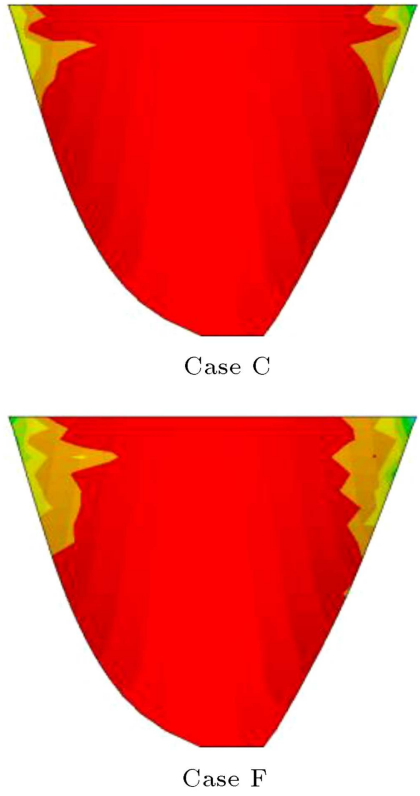

$-0.369 \mathrm{E}+07$

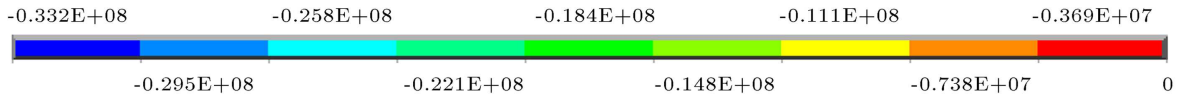

Figure 15. Envelopes of the 3rd principal stresses on up-stream face.

modelled AAR-affected case study showed significant dependency of the seismic responses on the earthquake excitation time. It is observed, prior to almost $50 \%$ of the reaction progression, that earthquake effects on the stresses are significant (Cases A, B, and C); however, the dependency decreased when earthquake was assumed to occur at any time after passing an ARI of about $50 \%$ (Cases C, D, and E). However, the differences were milder when one traced the post-earthquake responses. Highly reliable judgment on the current 
conclusions should be left for further considerations. Finally, it may be inferred that evaluating behavior of the AAR-affected dams under seismic loadings is complicated, and only case-by-case simulations may be proposed.

\section{References}

1. Charlwood, R.G., Steele, R.R., Solymar, Z.V., and Curtis, D.D. "A review of alkali-aggregate reaction in hydro-electric plants and dams", In Int. Conf. on Alkali-Aggregate Reactions in Hydro-Electric Plants and Dams: New Brunswick, Canada (1992).

2. Huang, M. and Pietruszczak, S. "Modeling of thermomechanical effects of alkali-silica reaction", Journal of Engineering Mechanics, 125(4), pp. 476-485 (1999).

3. Ulm, F.J., Coussy, O., Kefei, L., Larive, C. "Thermochemo-mechanics of ASR expansion in concrete structure", Journal of Engineering Mechanics, 126(3), pp. 232-242 (2000).

4. Malla, S. and Wieland, M. "Analysis of an arch-gravity dam with a horizontal crack", Computers \& Structures, 72(1-3), pp. 267-278 (1999).

5. Parvini, M., Pietruszczak, S., and Gocevski, V. "Seismic analysis of hydraulic structures affected by alkaliaggregate reaction: a case study", Canadian Journal of Civil Engineering, 28(2), pp. 332-338 (2001).

6. Saouma, V., Perotti, L., and Shimpo, T. "Stress analysis of concrete structures subjected to alkaliaggregate reactions", ACI Structural Journal, 104(5), pp. 532-541 (2007).

7. Grimal, E., Sellier, A., Multon, S., Le Pape, Y., and Bourdarot, E. "Concrete modelling for expertise of structures affected by alkali aggregate reaction", Cement and Concrete Research, 40(4), pp. 502-507 (2010).

8. Tokmechi, Z. "The probability of RCC dams cracking due to NASR", Aust. J. Basic Appl. Sci., 5(5), pp. 768-775 (2011).

9. Wang, J., Jin, F., and Zhang, C. "Seismic safety of arch dams with aging effects", Science China Technological Sciences, 54(3), pp. 522-530 (2011).

10. Pan, J., Xu, Y., Jin, F., and Zhang, C. "A unified approach for long-term behavior and seismic response of AAR-affected concrete dams", Soil Dynamics and Earthquake Engineering, 63, pp. 193-202 (2014).

11. Pan, J., Feng, Y., Xu, Y., Jin, F., Zhang, C., and Zhang, B. "Chemo-damage modeling and cracking analysis of AAR-affected concrete dams", Science China Technological Sciences, 56(6), pp. 1449-1457 (2013).

12. Pan, J., Feng, Y., Wang, J., Sun, Q., Zhang, C., and Owen, D. "Modeling of alkali-silica reaction in concrete: a review", Frontiers of Structural and Civil Engineering, 6(1), pp. 1-18 (2012).

13. Mirzabozorg, H. "Staggered solution scheme for threedimensional analysis of dam reservoir interaction", Dam Engineering, 3, pp. 147-179 (2003).

14. Hariri-Ardebili, M. and Mirzabozorg, H. "Numerical simulation of reservoir fluctuation effects on nonlinear dynamic response of concrete arch dams", Advances in Fluid Mechanics VIII (AFM), WIT Press, Algarve, Portugal, pp. 427-438 (2010).

15. Saouma, V. and Perotti, L. "Constitutive model for alkali-aggregate reactions", ACI Materials Journal, 103(3), p. 194 (2006).

16. Lamea, M. and Mirzabozorg, H. "Simulating nonlinear behavior of AAR-affected arch dams including detection of crack profiles", Arabian Journal for Science and Engineering, 40(2), pp. 329-341 (2014).

17. Hariri-Ardebili, M. and Mirzabozorg, H. "Feasibility study of Dez arch dam heightening based on nonlinear numerical analysis of existing dam", Archives of Civil Engineering, 59(1), pp. 21-49 (2013).

18. Hariri-Ardebili, M.A. and Mirzabozorg, H. "Feasibility study of Dez arch dam heightening based on nonlinear numerical analysis of existing dam", Archives of Civil Engineering, 59(1), pp. 21-49 (2013).

19. Mirzabozorg, H., Hariri-Ardebili, M., Shirkhan, M., and Seyed-Kolbadi, S. "Mathematical modeling and numerical analysis of thermal distribution in arch dams considering solar radiation effect", The Scientific World Journal, 2014 (2014).

20. Lamea, M. and Mirzabozorg, H. "Evaluating sensitivity of an AAR-affected concrete arch dam to the effects of structural joints and solar radiation", Strength of Materials, 47(2), pp. 341-354 (2015).

\section{Biographies}

Mohsen Lamea is now an Assistant Professor at Civil Engineering Department, Islamic Azad UniversityKashan Branch, Kashan, Iran. He has received his PhD in Structural Engineering from K.N. Toosi University of Technology, Tehran, Iran. His research interests include dam engineering, computational mechanics, and numerical simulations.

Hasan Mirzabozorg is now an Associate Professor at Civil Engineering Department, K.N. Toosi University of Technology, Tehran, Iran. He received his $\mathrm{PhD}$ from Sharif University of Technology in Tehran. His research interests are dam engineering, computational mechanics, and numerical simulations. 